\title{
Tribological behavior of black phosphorus nanosheets as water-based lubrication additives
}

\author{
Qingjuan WANG ${ }^{1}$, Tingli HOU ${ }^{1}$, Wei WANG ${ }^{1, *}$, Guoliang ZHANG ${ }^{2}$, Yuan GAO $^{1}$, Kuaishe WANG $^{1}$ \\ ${ }^{I}$ School of Metallurgy Engineering, Xi' an University of Architecture and Technology, Xi'an 710055, China \\ ${ }^{2}$ School of Mechanical Engineering, Tianjin University of Technology and Education, Tianjin 300222, China \\ Received: 02 June 2020 / Revised: 30 July 2020 / Accepted: 14 October 2020 \\ (C) The author(s) 2020 .
}

\begin{abstract}
Black phosphorus (BP) with a layered structure has been used gradually as a lubrication additive in the tribological area. In this study, BP powders are produced via an easy method of high-energy ball milling using red phosphorus as a raw material. Subsequently, BP nanosheets are prepared via liquid exfoliation in N-methyl pyrolidone solvent. The tribological behavior of BP nanosheets as water-based lubrication additives (BP-WL) is evaluated under Ti6Al4V (TC4)/GCr15 contact. The results suggest that the $70 \mathrm{mg} / \mathrm{L} \mathrm{BP-WL}$ sample exhibits excellent lubrication performance, whose coefficient of friction (COF) and ball wear rate reduced by $32.4 \%$ and $61.1 \%$, respectively, compared with those of pure water. However, as the load increased, the tribological properties of BP-WL reduced gradually because of the agglomeration of BP nanosheets. Based on tribological experiments and worn surface analysis, boundary lubrication mechanisms are proposed. The friction reduced, which is primarily attributed to the low interlaminar shear and adsorption of $\mathrm{BP}$ nanosheets. In addition, a tribochemical reaction film comprising $\mathrm{TiO}_{2}, \mathrm{Al}_{2} \mathrm{O}_{3}$, and $\mathrm{Fe}_{2} \mathrm{O}_{3}$ effectively protects the surface of titanium alloy/steel from wear. This new water-based lubrication additive can be used to process titanium alloys.
\end{abstract}

Keywords: black phosphorus (BP); tribological behavior; lubrication additives; titanium alloy/steel friction pairs

\section{Introduction}

Owing to their excellent physical-chemical properties, titanium alloys have been widely used in aviation, aerospace, and ocean engineering [1, 2]. However, titanium and its alloys are difficult-to-cut metal; hence, high friction is produced between the workpiece and tool during cutting. Titanium alloys have lower thermal conductivity and elastic modulus, and their chemical activity is extremely high; therefore, adhesive wear occurs easily on the surface of titanium alloys [3, 4]. High temperature, friction, and wear are presented in the cutting zone, resulting in high machining costs, low accuracy, and poor workpiece surface quality. These defects hinder the further application of titanium alloys in aviation and aerospace [5-7]. Lubrication is an effective method to solve the major processing problems encountered. However, owing to the extremely poor tribological properties of titanium alloys, they are difficult to lubricate during manufacturing using traditional lubricants used in metal plastic processes [8-12]. Wang et al. [8] added molecularly modified $\mathrm{Cu}$ nanoparticles capped with $\mathrm{O}, \mathrm{O}^{\prime}$-di-n-octyldithiophosphate (nano$\mathrm{Cu}$-DTP) particles into rapeseed oil to study the lubricating performance of a Ti6Al4V disk/AISI52100 ball and discovered that Cu-DTP lubricants can increase the wear resistance of TC4 at low applied loads. Jiménez et al. [13-15] studied the lubricating properties of ionic liquids as lubricants on titanium

* Corresponding author: Wei WANG, E-mail: gackmol@163.com 
alloy/steel friction pairs at different temperatures and discovered that ionic liquids can reduce the coefficient of friction (COF) at $300{ }^{\circ} \mathrm{C}$ and improve the lubrication performance of ionic liquids. Currently, a few water-based lubrication additives are used for processing titanium alloys. To achieve highly efficient titanium alloy machining, new lubricating materials and methods must be sought.

In metal cutting, a lower concentration of phosphorusbased additives can significantly increase the tribological properties of the lubricants used. The phosphorus elements in the base oil, which provide nutrients, are beneficial to the reproduction of microorganisms and improve the biodegradability of lubricants [16-18]. Different computational studies have analyzed the anisotropy and superlubric properties of phosphorene based on dynamic and static simulations $[19,20]$. Black phosphorus (BP) offers attractive thermodynamic stability, an adjustable bandgap, and favorable mechanical properties [21-23]. Currently, $\mathrm{BP}$ is being investigated as a novel lubrication additive in base oil [24-29]. Lv et al. [24] discovered that the microfriction of few-layer BP nanosheets presented layer dependence and anisotropic friction. In addition, the degradation of BP nanosheets in a moist environment can improve their tribological properties [26]. In a previous study by our group, modified BP nanosheets as water-based lubrication additives presented superlubricity characteristics with $\mathrm{Si}_{3} \mathrm{~N}_{4}$ ball/ $/ \mathrm{SiO}_{2}$ disk as the friction pairs [27]. With regard to oil-based lubrication additives, the results suggested that BP nanosheets possessed outstanding carry capacity under high loads and excellent lubricating characteristics at ultralow concentrations [28]. The lubrication performance of $\mathrm{BP}$ nanosheets is not only related to its slippage but also its friction interface film, particularly under high loads (contact stress above 1.67 GPa) [29]. Although some investigations regarding $\mathrm{BP}$ nanosheets as lubrication additives have been conducted on steel/ steel friction pairs in oil or water- based lubricants, few studies have revealed the lubrication mechanisms of titanium alloy/steel friction pairs under BP lubrication.

This investigation focused on BP nanosheets as water-based lubrication additives (BP-WL) in the processing of titanium alloys. The tribological pro- perties of BP-WL were investigated under GCr15 ball/TC4 titanium alloy disk contact. The lubrication mechanisms of BP-WL are discussed and analyzed herein.

\section{Experimental}

\subsection{Materials and methods}

In this investigation, red phosphorus (RP), N-methyl pyrrolidone (NMP), absolute ethanol, and petroleum ether were used as raw materials. All chemicals and reagents were used without further purification. Ultrapure water was produced using an ultrapure water purifier.

The preparation process of BP-WL is shown in Fig. 1. The RP powders were ball-milled using a QM-3B high speed vibrating ball mill. The ball-to-powder weight ratio, ball milling rotation speed, and milling time were 50:1, 1,200 rpm, and 0.5-2 h, respectively. After high-energy ball milling (HEBM) was performed, BP powders were collected. BP nanosheets were obtained via liquid exfoliation in an NMP solvent. First, pristine BP powders of weighing 30, 90, and $150 \mathrm{mg}$ were added to $30 \mathrm{~mL}$ of the NMP solvent to form $\mathrm{BP}$ dispersions at diverse initial concentrations, i.e., $\left(C_{i}\right): C_{i 1}=1 \mathrm{mg} / \mathrm{mL}, C_{i 2}=3 \mathrm{mg} / \mathrm{mL}$, and $C_{i 3}=5$ $\mathrm{mg} / \mathrm{mL}$. Next, for each concentration, after an ultrasonic treatment for $10 \mathrm{~h}$ in an ice bath, the dispersions were further centrifuged for $20 \mathrm{~min}$ at 3,500 rpm to gather the supernatants; subsequently, the supernatants were further centrifuged for $30 \mathrm{~min}$ at $11,000 \mathrm{rpm}$ to collect the precipitates. Finally, the precipitates were washed repeatedly using deionized water and ethanol. Finally, the collected $\mathrm{BP}$ nanosheets were dispersed in pure water via ultrasonication and stirring for $10 \mathrm{~min}$ to obtain BP-WL. The concentrations of the obtained BP-WL were 35, 70, and $200 \mathrm{mg} / \mathrm{L}$, as shown in Table 1 .

Table 1 Resultant BP concentration for each initial BP concentration.

\begin{tabular}{ccc}
\hline $\begin{array}{c}\text { Concentration } \\
\left(C_{i}\right)\end{array}$ & $\begin{array}{c}\text { Initial BP } \\
\text { concentration }(\mathrm{mg} / \mathrm{L})\end{array}$ & $\begin{array}{c}\text { Resultant BP } \\
\text { concentration }(\mathrm{mg} / \mathrm{L})\end{array}$ \\
\hline$C_{i 1}$ & 1 & 35 \\
$C_{i 2}$ & 3 & 70 \\
$C_{i 3}$ & 5 & 200 \\
\hline
\end{tabular}




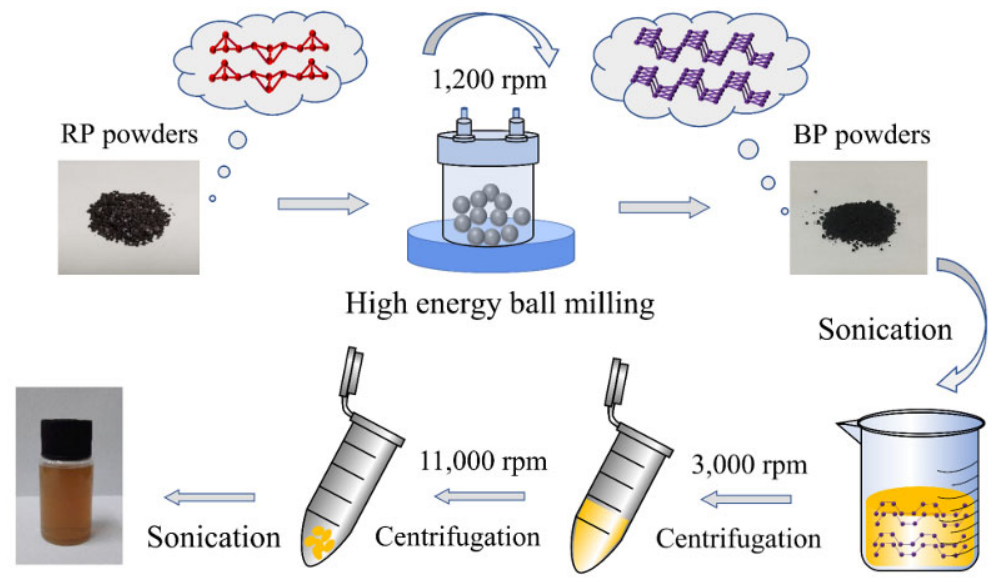

BP-WL Precipitates Supernatants BP in NMP solutions

Fig. 1 Schematic illustration of BP-WL preparation process.

\subsection{Tribological testing}

A ball-on-disc friction tester (UMT-5) was used. The friction pairs comprised GCr15 steel balls ( $\phi 6 \mathrm{~mm}$ ) and TC4 titanium alloy discs ( $\phi 24$ and $8 \mathrm{~mm})$. For comparison, ultrapure water was evaluated under the same conditions. Tribological tests were performed under different loads $(8-15 \mathrm{~N})$ at a rotating speed of $150 \mathrm{r} / \mathrm{min}$ for $30 \mathrm{~min}$. The corresponding contact stresses were calculated by using Hertz's contact theory as follows [30]:

$$
\begin{gathered}
P=\frac{4 W}{\pi a^{2}} \\
a=2\left(\frac{2}{3} \times \frac{W R}{E^{\prime}}\right)
\end{gathered}
$$

where $P, a, W, R$, and $E$ are the Hertz contact stress, contact diameter, applied load (8-15 N), ball radius, and effective elastic modulus, respectively. Furthermore, E was calculated using Eq. (3) [31].

$$
\frac{1}{E^{\prime}}=\frac{1}{2}\left(\frac{1-\mu_{1}^{2}}{E_{1}}+\frac{1-\mu_{2}^{2}}{E_{2}}\right)
$$

where $E_{1}(110 \mathrm{GPa})$ and $E_{2}(210 \mathrm{GPa})$ are the elastic moduli of the friction pairs; $\mu_{1}(0.34)$ and $\mu_{2}(0.30)$ are the Poisson ratios. The maximum contact stresses ranged from 1,000 to 1,300 MPa. The wear rates of the GCr15 balls were calculated as follows [32]:

$$
V=\left(\frac{\pi l}{6}\right)\left(\frac{3 d^{2}}{4}+l^{2}\right)
$$

$$
l=r-\sqrt{r^{2}-\frac{d^{2}}{4}}
$$

where $V, r$, and $d$ are the wear volume, ball radius, and wear scar diameter, respectively.

\subsection{Characterization}

The phases of the RP and BP powders were analyzed using X-ray diffraction (XRD, D/max2200PC); furthermore, their structures were analyzed via laser Raman spectrometry (HORIBA JYT64001). The micrographs and size distribution of the powders were observed via scanning electron microscopy (SEM, Gemini 300). The morphology and thickness of the BP nanosheets were observed via transmission electron microscopy (FEI Tecnai F20) and atomic force microscopy (AFM, NT-MDT Prima). The chemical compositions of the worn surfaces were identified using X-ray photoelectron spectroscopy (XPS, Thermo ESCALAB 250XI). The worn surfaces of the friction pairs were evaluated via SEM and energy dispersive spectroscopy (EDS) to obtain the elemental distribution. A three-dimensional (3D) white light profilometer was used to analyze the TC4 discs. Furthermore, Raman spectroscopy was performed to analyze the worn surface.

\section{Results and discussion}

\subsection{Materials characterization}

To investigate the morphologies and phase structures 
of the powders, an SEM image of the RP powder was obtained, as presented in Fig. 2(a). The initial RP powders were spherical, and the size ranged between 2 and $8 \mu \mathrm{m}$. Figure 2(b) shows the XRD patterns of the RP powder after different milling time. Two broad diffraction peaks of RP were observed at $30^{\circ}$ and $55^{\circ}$, indicating that the RP structure was amorphous. After milling for $0.5 \mathrm{~h}$, the two broad peaks disappeared, and diffraction peaks were detected at $26.480^{\circ}, 35.008^{\circ}$, and $55.892^{\circ}$. These results suggest that the amorphous $\mathrm{RP}$ was transformed into BP [33]. Compared with $\mathrm{RP}$, the intensity of the diffraction peaks of BP improved with increasing milling time. A local high-energy region was formed by the significant mechanical energy generated within a short time, and this energy was conducive to the phase transformation [34]. After HEBM for $2 \mathrm{~h}$, the RP was completely transformed into BP. In addition, a shift occurred at the (111) crystal plane of BP. This might be attributed to the grain refinement of $\mathrm{BP}$ as the milling time increased. To further confirm the phase transformation from RP to $\mathrm{BP}$, the corresponding Raman spectra were characterized. As shown in Fig. 2(c), the characteristic peak appeared at $350 \mathrm{~cm}^{-1}$, which belongs to the B1 vibrational mode of RP. After HEBM for $0.5 \mathrm{~h}$, the broad peak of RP in the Raman spectrum disappeared. Meanwhile, new diffraction peaks appeared at 357.4, 431.7, and $460 \mathrm{~cm}^{-1}$. According to Refs. [35, 36], those peaks indicate the crystal structure of $\mathrm{BP}$, corresponding to phonon modes $A_{\mathrm{g}}^{1}, B_{2 \mathrm{~g}}$, and $A_{\mathrm{g}}^{2}$, respectively. The intensity of $A_{\mathrm{g}}^{2}$ was higher than that of $B_{2 g}$ owing to the excitation laser polarization along the armchair direction [37, 38]. To analyze the micrographs and elementary composition of the BP powders, the SEM images and EDS analysis of the BP powders after HEBM for $2 \mathrm{~h}$ are shown in Figs. 2(d)-2(f). The particle size ranged from nanometers to micrometers. The high-magnification image in Fig. 2(e) exhibits the lamellar structure of BP. The EDS analysis shows that the mass ratios of $\mathrm{P}$ and $\mathrm{O}$ were $97.75 \%$ and $2.25 \%$, respectively.

Figure 3(a) shows the morphology of the BP nanosheets and the selected area electron diffraction (SAED) pattern. It was observed that some diffraction spots corresponding to the (020), (021), and (111) planes of the BP lattice appeared. The high-resolution transmission electron microscopy (HRTEM) image (Fig. 3(b)) further confirmed that the BP nanosheets were orthorhombic in the crystal structure and possessed high crystallinity. Figure 3(c) shows the AFM image of the BP nanosheets: The measured
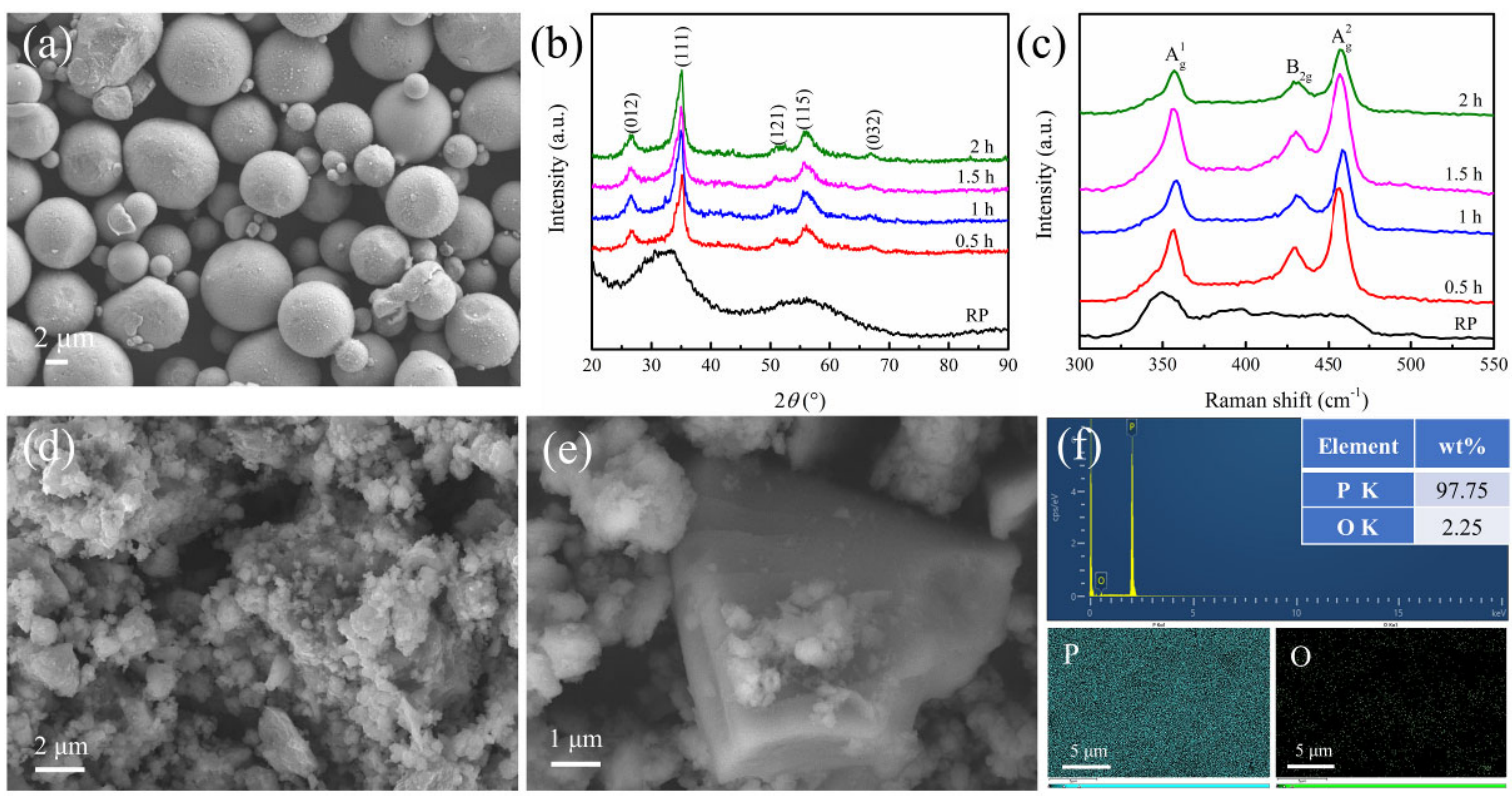

Fig. 2 (a) SEM image of RP powders; (b) XRD patterns; (c) Raman spectrum. (d-f) SEM images and EDS mapping of BP after HEBM for $2 \mathrm{~h}$. 

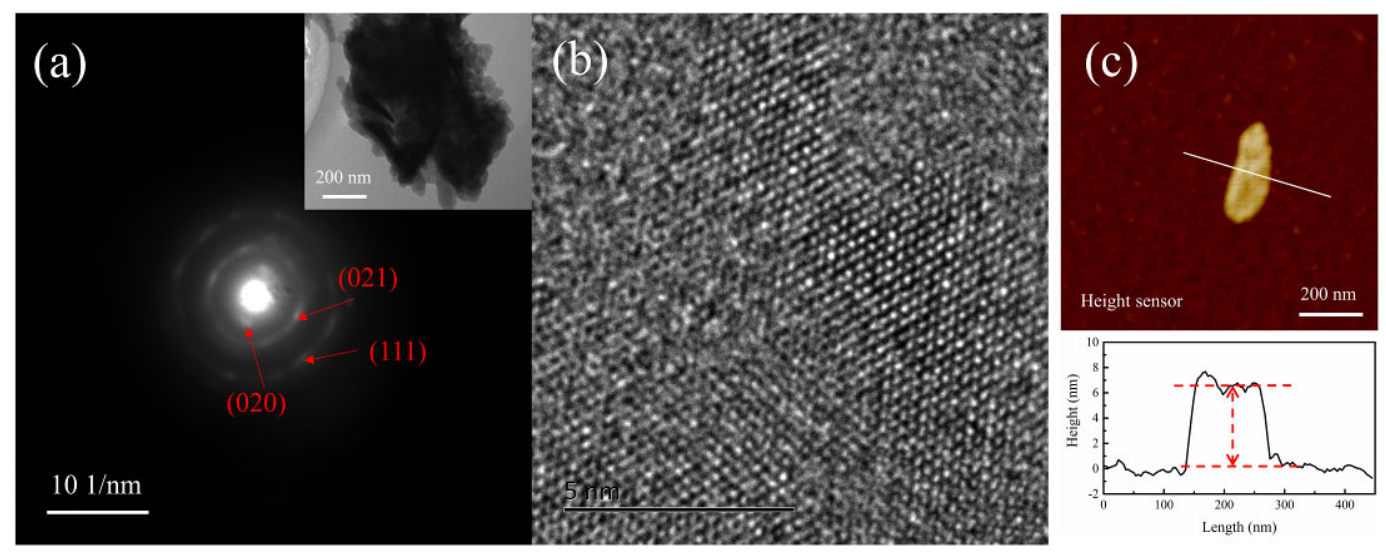

Fig. 3 (a) SAED pattern, (b) HRTEM image, and (c) AFM image of BP nanosheets.

width and thickness of the nanosheets were approximately 100 and $7 \mathrm{~nm}$, respectively. This indicates that the BP nanosheets prepared via liquid exfoliation exhibited the multilayer structure.

\subsection{Tribological properties of BP-WL}

Figure 4 shows the COF curves and wear rates for pure water and BP-WL at different concentrations $(35,70$, and $200 \mathrm{mg} / \mathrm{L})$ under $8 \mathrm{~N}$ and $150 \mathrm{r} / \mathrm{min}$. As shown in Fig. 4(a), during the first two minutes of the test, the COF of pure water first decreased to 0.28 and then continued to increase as friction continued to occur. In terms of third body lubrication, wear debris is the main reason for the decrease in the COF [39-41]. Moreover, oxides can be produced when a sphere rubs against disc surfaces because of frictional heat [42]. When the BP nanosheets were added to pure water, regardless of the content, the COF of BP-WL was always lower than that of pure water. During the friction process, the COF curves of BP-WL were stable after $5 \mathrm{~min}$. With the addition of $70 \mathrm{mg} / \mathrm{L}$ of $\mathrm{BP}-\mathrm{WL}$, the average COF and wear rate decreased, whereas the contents of BP-WL increased from 70 to $200 \mathrm{mg} / \mathrm{L}$, as shown in Fig. 4(b). The COF and wear rate of the $70 \mathrm{mg} / \mathrm{L}$ $\mathrm{BP}-\mathrm{WL}$ were the lowest, and they were reduced by $32.4 \%$ and $61.1 \%$, respectively. However, when the content of BP-WL increased to $200 \mathrm{mg} / \mathrm{L}$, the COF and wear rate of the GCr15 balls increased slightly, which might be due to the agglomeration of the BP nanosheets [43]. During friction processing, the BP nanosheets barely entered the contact region and adsorbed on the surface of the friction pairs at high concentrations [44].

Figure 5 shows the COFs and wear rates of the GCr15 balls lubricated by pure water and the $70 \mathrm{mg} / \mathrm{L}$ BP-WL under different loads. As shown in Fig. 5(a), the COF of pure water increased with the load and reached the highest value $(0.3061)$ at $15 \mathrm{~N}$. When the applied load was increased from 8 to $15 \mathrm{~N}$, the
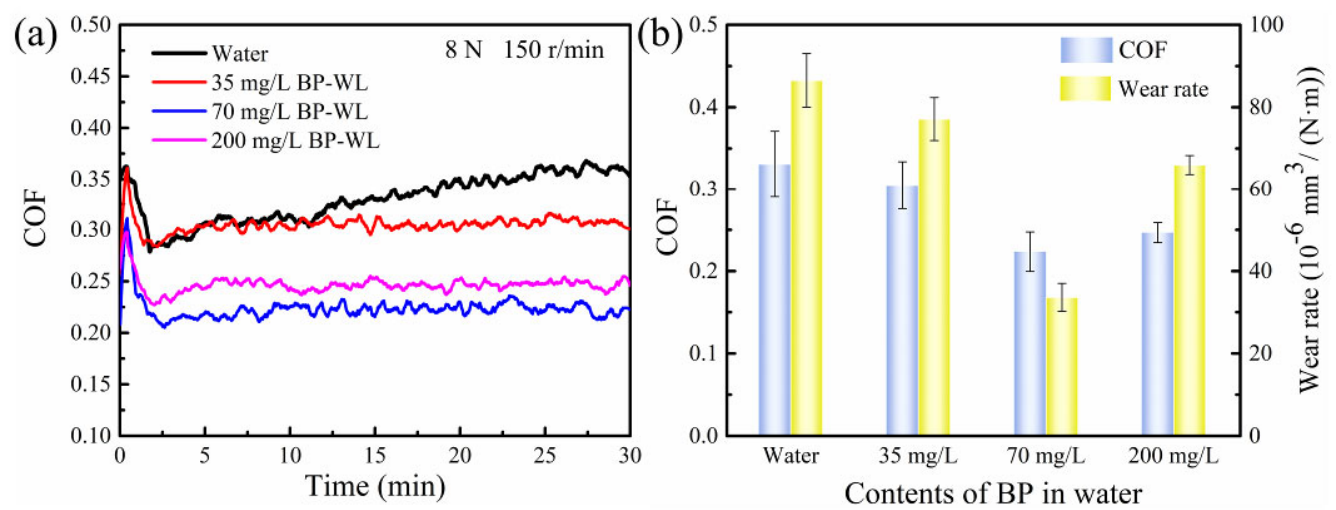

Fig. 4 (a) COF curves and (b) wear rates of GCr15 balls for pure water and BP-WL with different concentrations. 

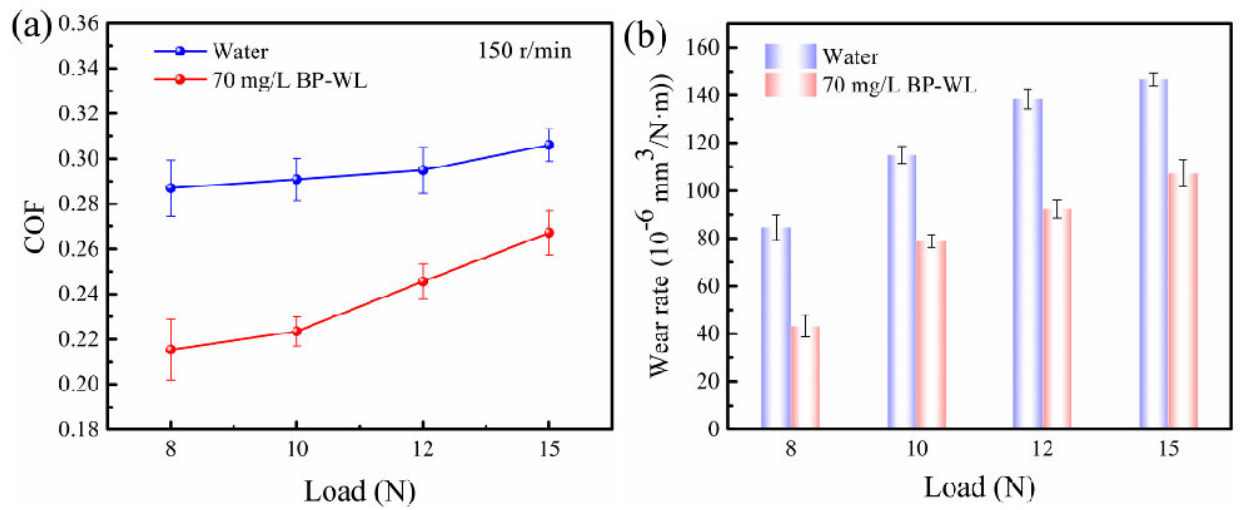

Fig. 5 (a) COF values and (b) wear rates of GCr15 balls for pure water and $70 \mathrm{mg} / \mathrm{L}$ BP-WL under different loads.

average COF of the $70 \mathrm{mg} / \mathrm{L} \mathrm{BP-WL}$ increased from 0.2154 to 0.2672 . Compared with the COF of pure water, the COF of BP-WL was lower than that of pure water under each load. As the loads increased, the wear rates of the GCr15 balls exhibited a similar trend (Fig. 5(b)). At a load of $8 \mathrm{~N}$, the pure water showed a relatively high wear rate of $84.63 \mathrm{~mm} /(\mathrm{N} \cdot \mathrm{m})$. On the contrary, the $70 \mathrm{mg} / \mathrm{L} \mathrm{BP-WL}$ presented an extremely low wear rate of $43.27 \mathrm{~mm}^{3} /(\mathrm{N} \cdot \mathrm{m})$. These results show that the $70 \mathrm{mg} / \mathrm{L}$ BP-WL is highly promising in improving friction-reducing and antiwear performance under lower loads.

\subsection{Worn surface analysis}

The SEM images of the worn surfaces of the GCr15 balls and TC4 disks at different concentrations under $8 \mathrm{~N}$ and $150 \mathrm{r} / \mathrm{min}$ are shown in Fig. 6. As shown from the worn surface of the GCr15 balls in Figs. 6(a)-6(d), it is clear that the wear scar on the surface of the balls is elliptical. This can be explained by the fact that under the external load, the local deformation between the sphere and disc is the main factor that formed the elliptic shape $[45,46]$. The difference in hardness between the GCr15 ball $\left(650 \pm 17 \mathrm{HV}_{0.3}\right)$ and TC4 disc $\left(345 \pm 15 \mathrm{HV}_{0.3}\right)$ resulted in a local deformation. Because of the worn TC4 disk material during friction and wear, the contact area in the vertical direction was higher than that in the sliding direction [47]. The wear scars of the GCr15 balls lubricated with pure water (Fig. 6(a)) was rough, with severe wear and wear debris. By contrast, the worn surface lubricated by BP-WL on the surface of the GCr15 ball showed slight traces of wear, and the wear area decreased. In particular, the surface lubricated by the $70 \mathrm{mg} / \mathrm{L}$ BP-WL (Fig. 6(c)) barely exhibited worn marks, and the wear area was the smallest among those of all lubricants with different concentrations. However, a small amount of debris was observed on the surface at a relatively high concentration of BP-LP (Fig. 6(d)). This is because the agglomeration of BP nanosheets resulted in high friction and wear on the frictional interface [48, 49]. As shown in Fig. 6(e), the worn surface of the TC4 titanium alloy disc lubricated by pure water was scratched to a width of approximately $762 \mu \mathrm{m}$, which was much wider than those shown in Figs. 6(f)-6(h). In addition, deep furrows and scratches were observed in the wear scar lubricated by pure water. As the concentration of BP-WL increased from 35 to $200 \mathrm{mg} / \mathrm{L}$, the wear widths first decreased and subsequently increased. The minimum width of the wear track was $680 \mu \mathrm{m}$ at $70 \mathrm{mg} / \mathrm{L}$. As shown in Fig. 6(g), the worn surface of the disk became smooth. This indicates the good lubrication effect of the BP nanosheets.

Figure 7 shows the EDS images of the worn surface of TC4 disks lubricated by pure water and BP-WL under $8 \mathrm{~N}$ and $150 \mathrm{r} / \mathrm{min}$. As shown in Fig. 7(a), deep grooves and severe desquamation appeared on the worn surface lubricated by pure water. After adding the BP nanosheets into pure water, the pits on the surface of TC4 disk were filled by a large amount of BP nanosheets regardless of the BP-WL concentration used (Figs. 7(b)-7(d)). Three main elements were detected on the frictional surface, i.e., $\mathrm{Ti}, \mathrm{Fe}$, and $\mathrm{P}$. The detected $\mathrm{Ti}$ elements were primarily from the TC4 matrix. Additionally, the 

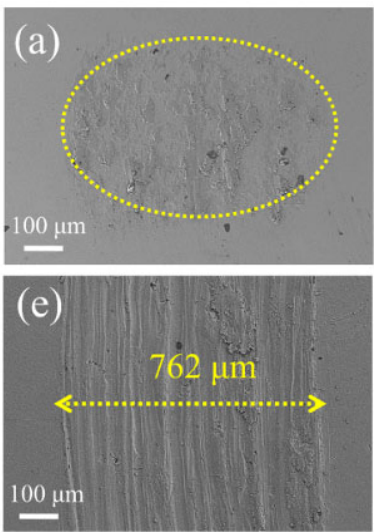
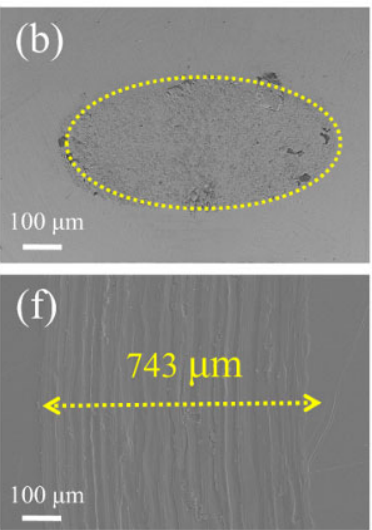
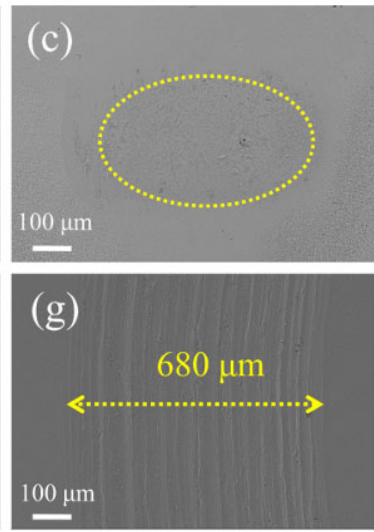
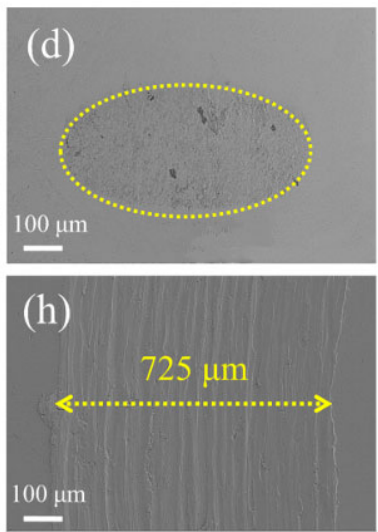

Fig. 6 (a-d) SEM images of worn surface of GCr15 balls lubricated by pure water, 35, 70, and 200 mg/mL BP-WL, respectively. (e-h) SEM images of worn surface of TC4 disks lubricated by pure water, 35, 70, and 200 mg/mL BP-WL, respectively.
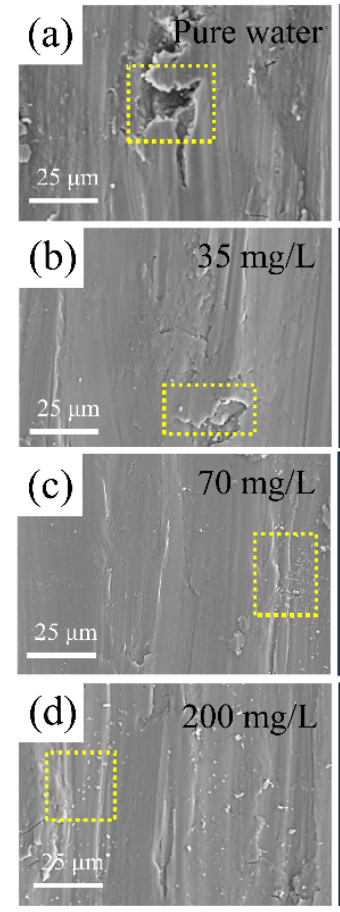
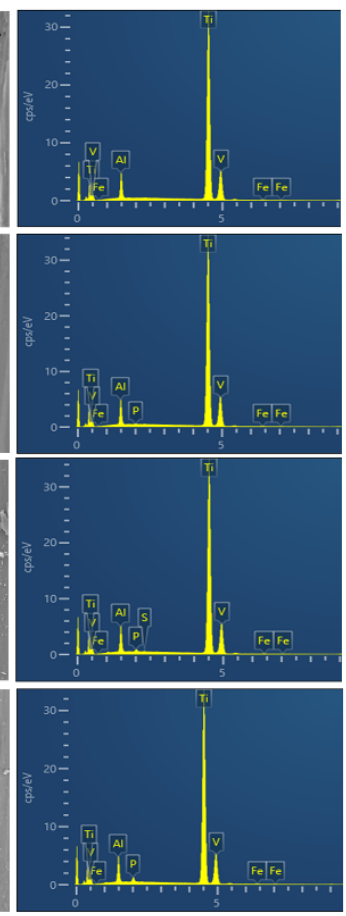
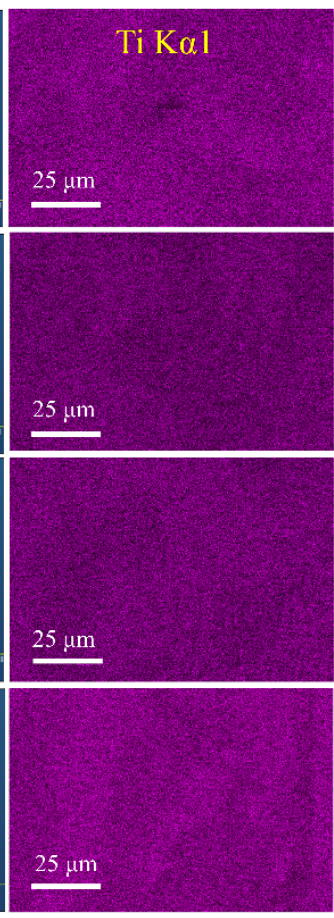
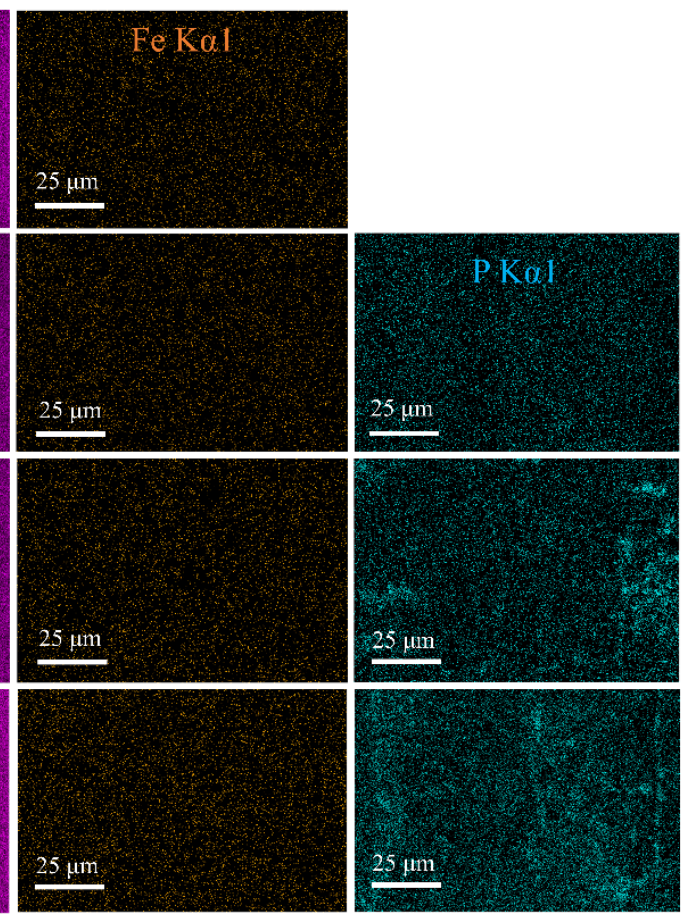

Fig. 7 EDS images of worn surface of TC4 disks lubricated by (a) pure water and BP-WL with different concentrations: (b) 35 $\mathrm{mg} / \mathrm{L}$, (c) $70 \mathrm{mg} / \mathrm{L}$, and (d) $200 \mathrm{mg} / \mathrm{L}$.

Fe detected on the surface of TC4 disk was transferred from the GCr15 ball. Furthermore, P appeared on the worn surface, indicating that the BP nanosheets had adsorbed on the surface of the TC4 titanium alloy disk. As the concentration of BP-WL increased, the contents of $\mathrm{P}$ increased gradually.

The morphology and full profiles of the worn surfaces under $8 \mathrm{~N}$ and $150 \mathrm{r} / \mathrm{min}$ were evaluated using a 3D profilometer (Fig. 8). The width and depth of wear tracks of the TC4 disk decreased as the concentration of BP-WL increased from 0 to 70 $\mathrm{mg} / \mathrm{L}$ and subsequently increased from 70 to 200 $\mathrm{mg} / \mathrm{L}$. In addition, the wear volume lubricated by pure water was $0.452 \mathrm{~mm}^{3}$. As the concentration of BP-WL increased from 35 to $70 \mathrm{mg} / \mathrm{L}$, the wear volume decreased from 0.445 to $0.359 \mathrm{~mm}^{3}$. However, the wear volume increased to $0.411 \mathrm{~mm}^{3}$ at $200 \mathrm{mg} / \mathrm{L}$. This is attributable to the low concentration of $\mathrm{BP}-\mathrm{WL}$, which rendered it much easier for the 
(a)
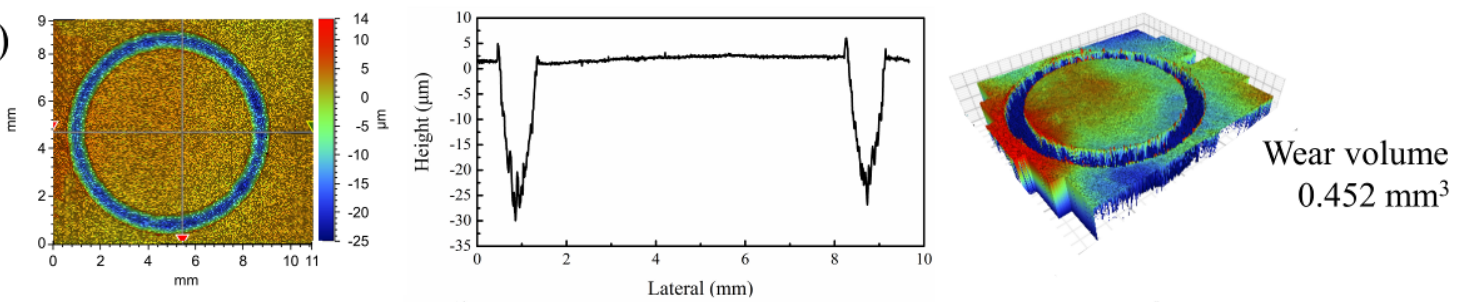

(b)
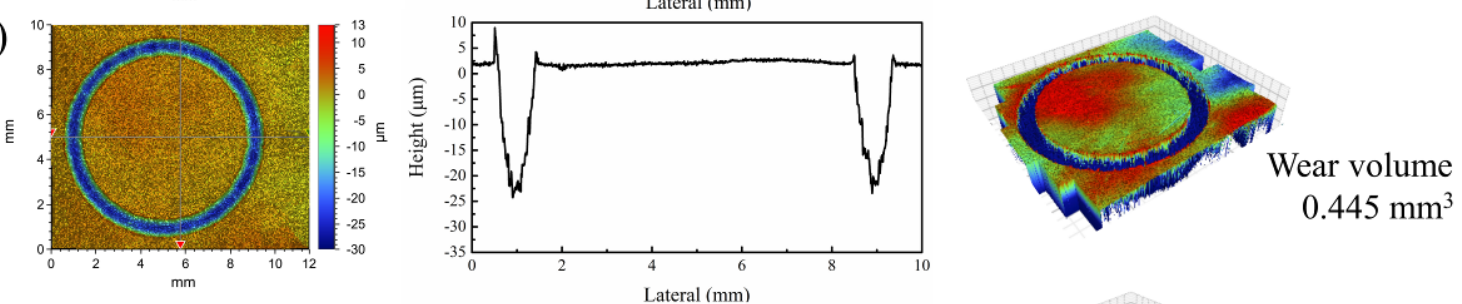

(c)
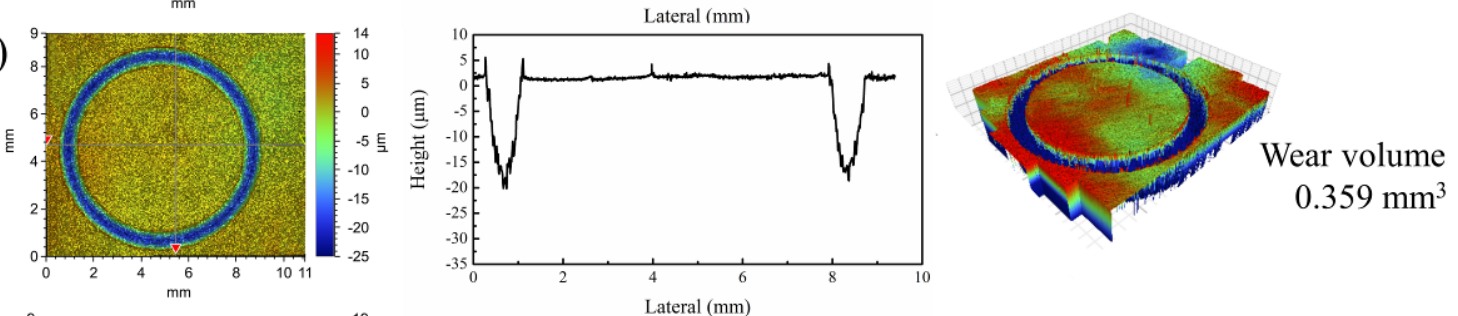

(d)
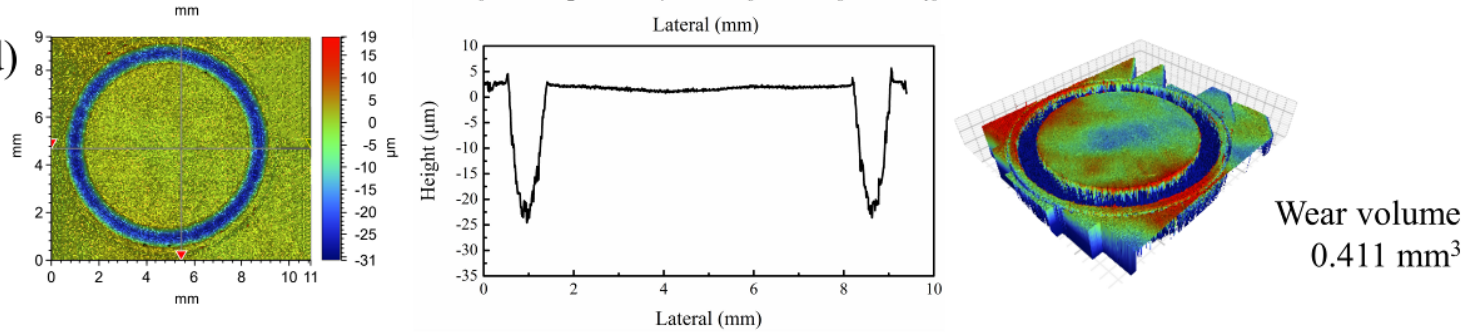

Fig. 8 3D Micrographs and profiles of wear tracks of TC4 disks lubricated by (a) pure water and BP-WL with different concentrations: (b) $35 \mathrm{mg} / \mathrm{L}$, (c) $70 \mathrm{mg} / \mathrm{L}$, and (d) $200 \mathrm{mg} / \mathrm{L}$.

nanosheets to enter the contact area and achieve a better lubricating effect compared with the high concentration of lubricants [39]. These results clearly demonstrate that BP-WL can significantly improve the anti-wear performance of pure water for titanium alloy/steel contacts.

Figure 9(a) shows the optical microscopy image of the worn surface of the TC4 disc lubricated by the $70 \mathrm{mg} / \mathrm{L} \mathrm{BP-WL}$ under $8 \mathrm{~N}$ and $150 \mathrm{r} / \mathrm{min}$. Some dark patches appeared on the worn surface and they might be the tribochemical reaction film. To further identify their chemical compositions, Raman and XPS analyses were adopted (Figs. 9(b)-9(i)). From the Raman spectrum (Fig. 9(b)), the characteristic peaks of $A_{\mathrm{g}}^{1}, B_{2 \mathrm{~g}}$, and $A_{\mathrm{g}}^{2}$ at approximately 360,430 , and $460 \mathrm{~cm}^{-1}$, respectively, confirmed the presence of BP nanosheets [35]. This suggests that an adsorption film had formed between two contact surfaces. The formed protective film can provide effective coverage of the friction surface. Figure 9(c) illustrates the full spectrum on the wear scar of the disk lubricated with the $70 \mathrm{mg} / \mathrm{L}$ BP-WL; C 1s, O 1s, Fe 2p, Ti 2p, Al 2p, and P 2p were detected. As shown in Fig. 9(d), the three C 1s peaks located at 284.6, 285.9, and $288.0 \mathrm{eV}$ mainly existed in the form of $\mathrm{C}-\mathrm{H} / \mathrm{C}=\mathrm{H}, \mathrm{C}-\mathrm{O}$, and $\mathrm{C}=\mathrm{O}$ [50]. The $\mathrm{O} 1$ s peaks at $530.4 \mathrm{eV}$ (Fig. 9(e)) and the $\mathrm{Fe} 2 \mathrm{p}_{3 / 2}$ at $710.9 \mathrm{eV}$ (Fig. 9(f)) both corresponded to the chemical state of oxygen in $\mathrm{Fe}_{2} \mathrm{O}_{3}[51,52]$. $\mathrm{Fe}_{2} \mathrm{O}_{3}$ appeared owing to the oxidation of Fe during the tribochemical reaction. The $\mathrm{O} 1 \mathrm{~s}$ peak at $531.1 \mathrm{eV}$ and the $\mathrm{Al} 2 \mathrm{p}$ peak at $74.7 \mathrm{eV}$ (Fig. 9(h)) both indicated the existence of $\mathrm{Al}_{2} \mathrm{O}_{3}$ [53]. As shown in Fig. 9(g), the Ti 2p XPS spectrum exhibited doublet peaks at 458.5 and $464.2 \mathrm{eV}$, which corresponded to the Ti $2 \mathrm{p}_{3 / 2}$ and Ti $2 \mathrm{p}_{1 / 2}$ characteristic peaks of $\mathrm{Ti}^{4+}$ inside the $\mathrm{TiO}_{2}$ lattice, respectively [54]. The O 1s peak at $529.5 \mathrm{eV}$ was attributed to $\mathrm{O}^{2-}$ inside the 

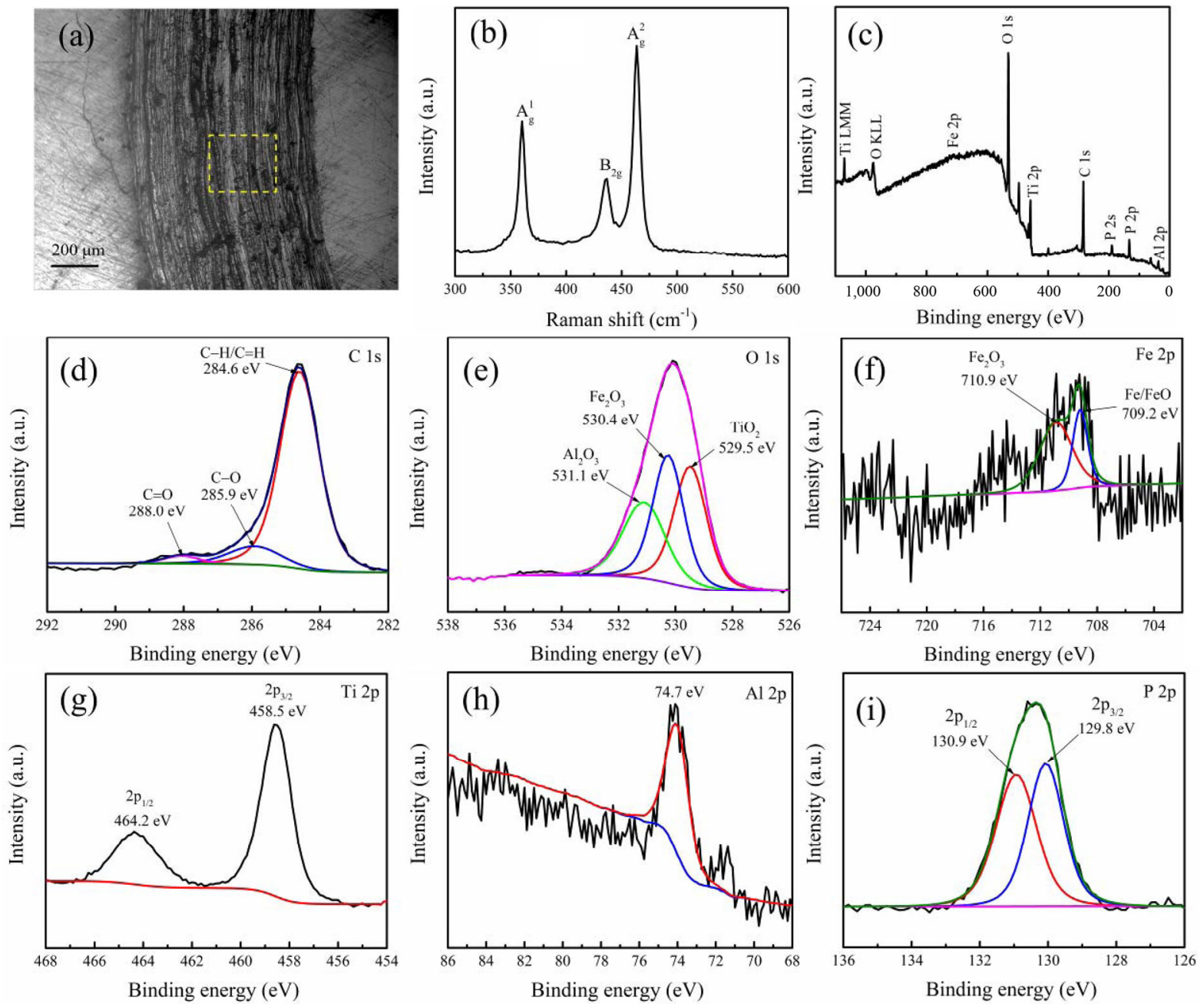

Fig. 9 (a) Optical microscopy image; (b) Raman analysis; (c-i) the XPS spectra of worn surface lubricated with $70 \mathrm{mg} / \mathrm{L}$ BP-WL.

$\mathrm{TiO}_{2}$ lattice [55]. These oxides indicate that the tribochemical reaction occurred during the friction process. The two typical peaks located at 129.8 and $130.9 \mathrm{eV}$ were assigned to $\mathrm{P} 2 \mathrm{p}_{3 / 2}$ and $\mathrm{P} 2 \mathrm{p}_{1 / 2}$ in the $\mathrm{P} 2 \mathrm{p}$ spectrum, respectively. $\mathrm{P} 2 \mathrm{p}_{3 / 2}$ and $\mathrm{P} 2 \mathrm{p}_{1 / 2}$ are the characteristic peaks of crystalline BP [56]. It was confirmed that the BP nanosheets adhered to the worn surface. Therefore, the tribochemical reaction formed a film comprising $\mathrm{Fe}_{2} \mathrm{O}_{3}, \mathrm{Al}_{2} \mathrm{O}_{3}$, and $\mathrm{TiO}_{2}$ on the worn surface. These absorption film and tribochemical reaction film were key in reducing the friction and wear of the titanium alloy/steel contact.

\subsection{Lubrication mechanism of BP-WL}

Based on the results above and the worn surface analysis, a schematic illustration of the lubrication model of BP-WL is shown in Fig. 10. The lubrication mechanisms of BP-WL have been proposed [27, 28]. First, the interlayer shearing force in the water-based lubrication additives is critical to the frictionreducing ability. During the friction process, a few BP nanosheets entered the rubbing surfaces because of their low interlaminar shear stress. The maximum friction force occurred at the interface of the rough peak between the ball and disk. The BP nanosheets were exfoliated and absorbed on the surface of the friction pairs during sliding processing (Figs. 10(a) and 10(b)). The lamellar slip of the BP nanosheets was beneficial for reducing the $\mathrm{COF}[57,58]$. Moreover, BP-WL can form an adsorption film and a tribochemical film on the worn surfaces. Raman spectroscopy was confirmed that the BP nanosheets 


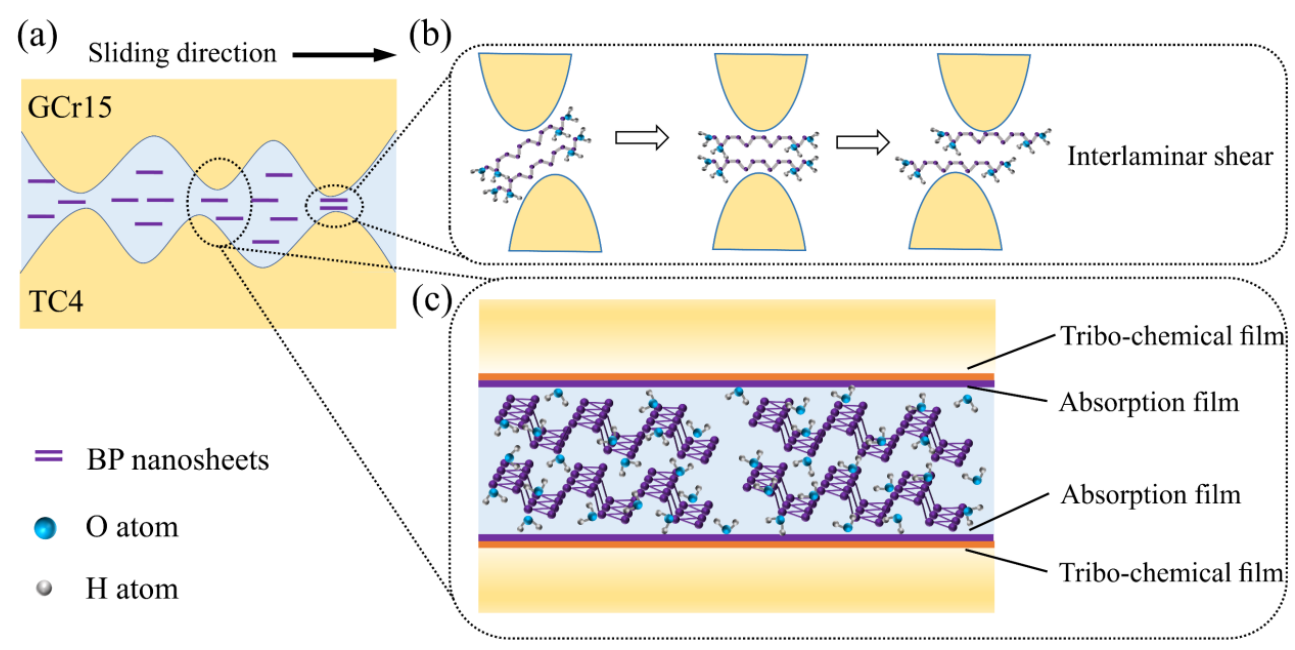

Fig. 10 Schematic illustration of the lubrication model of BP-WL.

were absorbed on the surface to form a BP film. According to classical lubrication theories, lubrication regimes can be identified in a lubrication regime map in terms of two variables, $g_{\mathrm{v}}$ and $g_{E}$, expressed as follows:

$$
\begin{aligned}
& g_{\mathrm{v}}=\frac{G W^{3}}{U^{2}} \\
& g_{\mathrm{E}}=\frac{W^{8 / 3}}{U^{2}}
\end{aligned}
$$

where $U=\eta V / E^{\prime} R, G=\alpha E^{\prime}, W=F / E^{\prime} R^{2}, R(3 \mathrm{~mm})$ is the radius of the GCr15 ball, $V(63.0 \mathrm{~mm} / \mathrm{s})$ is the linear velocity, $\eta$ is the viscosity of the lubricants, $\alpha$ is the viscosity-pressure coefficient, $E^{\prime}(162$ $\mathrm{GPa})$ is the finite elastic modulus, $F(8 \mathrm{~N})$ is the applied load, and $k(\approx 1)$ is the elliptical parameter. According to the Hamrock-Dowson theory, the theoretical minimum film thickness and the ratio $\gamma$ can be calculated using the following equation [46]:

$$
\begin{gathered}
h_{\min }=2.69 R \frac{G^{0.53} U^{0.67}}{W^{0.067}}\left(1-0.61 \mathrm{e}^{-0.73 k}\right) \\
\gamma=\frac{h_{\min }}{\sqrt{\sigma_{1}^{2}+\sigma_{2}^{2}}}
\end{gathered}
$$

where $\sigma_{1}$ and $\sigma_{2}$ are the roughness of the ball and disk, respectively $\left(\sigma_{1}=2.850 \mu \mathrm{m}, \sigma_{2}=4.424 \mu \mathrm{m}\right)$.

Through a series of calculations, $h_{\min }$ was obtained as approximately $13.07 \mathrm{~nm}$, and $\lambda$ was approximately 0.29 , i.e., smaller than 1 . Hence, the current lubrication state can be defined as the boundary lubrication regime [59]. Moreover, the XPS results suggested that complicated tribochemical reactions had occurred and consequently formed a tribochemical film composed of $\mathrm{TiO}_{2}, \mathrm{Fe}_{2} \mathrm{O}_{3}$, and $\mathrm{Al}_{2} \mathrm{O}_{3}$ on the rubbing surfaces. Hence, the $\mathrm{BP}$ nanosheets were bonded more tightly to the metal surface through the formation of chemical bonds [60]. The absorption and tribochemical films can effectively protect the contact surface from wear and improve the antiwear performance of the TC4/GCr15 friction pairs.

\section{Conclusions}

In summary, BP powders were prepared using HEBM, and BP nanosheets were fabricated via liquid exfoliation. The tribological behavior of BPWL was evaluated at different Hertzian contact stresses (1,119-1,281 MPa) under titanium alloy/steel contact. The results demonstrated that the $70 \mathrm{mg} / \mathrm{L}$ BP-WL exhibited the optimal lubrication performance. Its $\mathrm{COF}$ and wear rate decreased by approximately $32.4 \%$ and $61.1 \%$, respectively. The friction-reducing properties of the BP nanosheets were closely associated with their lamellar structure; furthermore, the BP nanosheets adsorbed on the worn surfaces through physical electrostatic actions. In addition, the anti-wear performance of BP-WL mainly depended on the adsorption and tribochemical films formed on the worn surfaces. These factors prevented the direct contact of the rubbing surfaces and significantly reduced the friction and wear, resulting in the superior tribological properties of the BP nanosheets. 


\section{Acknowledgements}

The authors gratefully thank the financial support from the Research Fund of the National Natural Science Foundation of China (Grant Nos. 51975450 and 51705277).

Open Access This article is licensed under a Creative Commons Attribution 4.0 International License, which permits use, sharing, adaptation, distribution and reproduction in any medium or format, as long as you give appropriate credit to the original author(s) and the source, provide a link to the Creative Commons licence, and indicate if changes were made.

The images or other third party material in this article are included in the article's Creative Commons licence, unless indicated otherwise in a credit line to the material. If material is not included in the article's Creative Commons licence and your intended use is not permitted by statutory regulation or exceeds the permitted use, you will need to obtain permission directly from the copyright holder.

To view a copy of this licence, visit http://creativecommons.org/licenses/by/4.0/.

\section{References}

[1] Ezugwu E O, Bonney J, Yamane Y. An overview of the machinability of aeroengine alloys. J Mater Process Technol 134(2): 233-253 (2003)

[2] Veiga C, Davim J P, Loureiro A J R. Properties and applications of titanium alloys: A brief review. Rev $A d v$ Mater Sci 32(2): 133-148 (2012)

[3] Shokrani A, Dhokia V, Newman S T. Environmentally conscious machining of difficult-to-machine materials with regard to cutting fluids. Int J Mach Tools Manuf 57: 83-101 (2012)

[4] Debnath S, Reddy M M, Yi Q S. Environmental friendly cutting fluids and cooling techniques in machining: A review. J Clean Prod 83: 33-47 (2014)

[5] Ezugwu E O. Key improvements in the machining of difficult-to-cut aerospace superalloys. Int J Mach Tools Manuf 45(12-13): 1353-1367 (2005)

[6] Kahles J F, Field M, Eylon D, Froes F H. Machining of titanium alloys. JOM 37(4): 27-35 (1985)

[7] Egaña A, Rech J, Arrazola P J. Characterization of friction and heat partition coefficients during machining of a $\mathrm{TiAl}_{6} \mathrm{~V}_{4}$ titanium alloy and a cemented carbide.
Tribol Trans 55(5): 665-676 (2012)

[8] Wang F, Bi Q L, Wang X B, Liu W M. Sliding friction and wear performance of $\mathrm{Ti}_{6} \mathrm{Al}_{4} \mathrm{~V}$ in the presence of surface-capped copper nanoclusters lubricant. Tribol Int 41(3): 158-165 (2008)

[9] Yang Y, Zhang C H, Dai Y J, Luo J B. Tribological properties of titanium alloys under lubrication of SEE oil and aqueous solutions. Tribol Int 109: 40-47 (2017)

[10] Cheng J, Yang J, Ma J Q, Bi Q L, Zhang X H, Fu L C, Li F, Zhu S Y, Liu W M. The tribological behavior of a $\mathrm{Ti}-46 \mathrm{Al}-2 \mathrm{Cr}-2 \mathrm{Nb}$ alloy under liquid paraffine lubrication. Tribol Lett 46(3): 233-241 (2012)

[11] Rahman M, Wang Z G, Wong Y S. A review on high-speed machining of titanium alloys. JSME INT $J$ C-MECH SY 49(1): 11-20 (2006)

[12] Sharma M D, Sehgal R. Experimental study of friction and wear characteristics of titanium alloy (Ti-6Al-4V) under lubricated sliding condition. Ind Lubricat Tribol 66(2): 174-183 (2014)

[13] Jiménez A E, Bermúdez M D. Ionic liquids as lubricants of titanium-steel contact. Part 2: Friction, wear and surface interactions at high temperature. Tribol Lett 37(2): 431-443 (2010)

[14] Espinosa T, Jiménez M, Sanes J, Jiménez A E, Iglesias M, Bermúdez M D. Ultra-low friction with a protic ionic liquid boundary film at the water-lubricated sapphirestainless steel interface. Tribol Lett 53(1): 1-9 (2014)

[15] Jiménez A E, Bermúdez M D. Ionic liquids as lubricants of titanium-steel contact. Tribol Lett 33(2): 111-126 (2009)

[16] Su F H, Chen G F, Huang P. Lubricating performances of graphene oxide and onion-like carbon as water-based lubricant additives for smooth and sand-blasted steel discs. Friction 8(1): 47-57 (2020)

[17] Dohda K, Boher C, Rezai-Aria F, Mahayotsanun N. Tribology in metal forming at elevated temperatures. Friction 3(1): 1-27 (2015)

[18] Xiong X J, Sun J L, Huang Y, Zhu G P. Application effect of p-containing additives in cold-rolling emulsion of copper plate. Lubricat Eng 35(10): 102-106 (2010)

[19] Losi G, Restuccia P, Righi M C. Superlubricity in phosphorene identified by means of $a b$ initio calculations. 2D Mater 7(2): 025033 (2020)

[20] Bai L C, Liu B, Srikanth N, Tian Y, Zhou K. Nano-friction behavior of phosphorene. Nanotechnology 28(35): 355704 (2017)

[21] Xing C, Zhang J H, Jing J Y, Li J Z, Shi F. Preparations, properties and applications of low-dimensional black phosphorus. Chem Eng J 370: 120-135 (2019)

[22] Qu G B, Liu W, Zhao Y T, Gao J, Xia T, Shi J B, Hu L G, Zhou W H, Gao J J, Wang H Y, et al. Improved biocompatibility of black phosphorus nanosheets by chemical modification. Angew Chem Int Ed 56(46): 
14488-14493 (2017)

[23] Jia J Y, Jang S K, Lai S, Xu J, Choi Y J, Park J H, Lee S. Plasma-treated thickness-controlled two-dimensional black phosphorus and its electronic transport properties. ACS Nano 9(9): 8729-8736 (2015)

[24] Lv Y, Wang W, Xie G X, Luo J B. Self-lubricating PTFE-based composites with black phosphorus nanosheets. Tribol Lett 66(2): 61 (2018)

[25] Chen H, Huang P, Guo D, Xie G X. Anisotropic mechanical properties of black phosphorus nanoribbons. J Phys Chem C 120(51): 29491-29497 (2016)

[26] Wu S, He F, Xie G X, Bian Z L, Luo J B, Wen S Z. Black phosphorus: Degradation favors lubrication. Nano Lett 18(9): 5618-5627 (2018)

[27] Wang W, Xie G X, Luo J B. Superlubricity of black phosphorus as lubricant additive. ACS Appl Mater Interfaces 10(49): 43203-43210 (2018)

[28] Wang W, Xie G X, Luo J B. Black phosphorus as a new lubricant. Friction 6(1): 116-142 (2018)

[29] Xu Y F, Yu J Y, Dong Y H, You T, Hu X G. Boundary lubricating properties of black phosphorus nanosheets in polyalphaolefin oil. J Tribol 141(7): 072101 (2019)

[30] Xu Y F, Geng J, Peng Y B, Liu Z C, Yu J Y, Hu X G. Lubricating mechanism of $\mathrm{Fe}_{3} \mathrm{O}_{4} @ \mathrm{MoS}_{2}$ core-shell nanocomposites as oil additives for steel/steel contact. Tribol Int 121: 241-251 (2018)

[31] Liu P X, Liu Y H, Yang Y, Chen Z, Li J J, Luo J B. Mechanism of biological liquid superlubricity of Brasenia schreberi mucilage. Langmuir 30(13): 38113816 (2014)

[32] Shen Y, Zhang D K, Wang D G, Xu L M. Effect of contact load on the fretting wear behavior of steel wire. Tribology 30(4): 404-408 (2010)

[33] Aldave S H, Yogeesh M N, Zhu W N, Kim J, Sonde S S, Nayak A P, Akinwande D. Characterization and sonochemical synthesis of black phosphorus from red phosphorus. 2D Mater 3(1): 014007 (2016)

[34] Zhou F C, Ouyang L Z, Zeng M Q, Liu J W, Wang H, Shao H Y, Zhu M. Growth mechanism of black phosphorus synthesized by different ball milling techniques. J Alloys Comp 784: 339-346 (2019)

[35] Rissi E N, Soignard E, McKiernan K A, Benmore C J, Yarger J L. Pressure-induced crystallization of amorphous red phosphorus. Solid State Commun 152(5): 390-394 (2012)

[36] Zhang Y Y, Rui X H, Tang Y X, Liu Y Q, Wei J Q, Chen S, Leow W R, Li W L, Liu Y J, Deng J Y, et al. Wet-chemical processing of phosphorus composite nanosheets for high-rate and high-capacity lithium-ion batteries. Adv Energy Mater 6(10): 1502409 (2016)

[37] Xia F N, Wang H, Jia Y C. Rediscovering black phosphorus as an anisotropic layered material for optoelectronics and electronics. Nat Commun 5: 4458 (2014)

[38] Du S N, Sun J L, Wu P. Preparation, characterization and lubrication performances of graphene oxide- $\mathrm{TiO}_{2}$ nanofluid in rolling strips. Carbon 140: 338-351 (2018)

[39] Wu H, Zhao J W, Xia W Z, Cheng X W, He A S, Yun J H, Wang L Z, Huang H, Jiao S H, Huang L, et al. A study of the tribological behaviour of $\mathrm{TiO}_{2}$ nano-additive water-based lubricants. Tribol Int 109: 398-408 (2017)

[40] Rapoport L, Leshchinsky V, Lvovsky M, Lapsker I, Volovik Y, Feldman Y, Popovitz-Biro R, Tenne R. Superior tribological properties of powder materials with solid lubricant nanoparticles. Wear 255(7-12): 794-800 (2003)

[41] Trezona R I, Allsopp D N, Hutchings I M. Transitions between two-body and three-body abrasive wear: Influence of test conditions in the microscale abrasive wear test. Wear 225-229: 205-214 (1999)

[42] Stott F H, Wood G C. The influence of oxides on the friction and wear of alloys. Tribol Int 11(4): 211-218 (1978)

[43] Peng D X, Chen C H, Kang Y, Chang Y P, Chang S Y. Size effects of $\mathrm{SiO}_{2}$ nanoparticles as oil additives on tribology of lubricant. Ind Lubricat Tribol 62(2): 111-120 (2010)

[44] Hooke C J. The elastohydrodynamic lubrication of heavily loaded point contacts. J Mech Eng Sci 22(4): 183-187 (1980)

[45] Xu T, Zhao J Z, Xu K. The ball-bearing effect of diamond nanoparticles as an oil additive. J Phys D Appl Phys 29(11): 2932-2937 (1996)

[46] Hu Y W, Wang Y X, Zeng Z X, Zhao H C, Li J L, Ge X W, Wang L P, Xue Q J, Mao C L, Chen S J. BLG-RGO: A novel nanoadditive for water-based lubricant. Tribol Int 135: 277-286 (2019)

[47] Wang W, Zhang G L, Xie G X. Ultralow concentration of graphene oxide nanosheets as oil-based lubricant additives. Appl Surf Sci 498: 143683 (2019)

[48] Ge X Y, Xia Y Q, Shu Z Y, Zhao X P. Conductive grease synthesized using nanometer ATO as an additive. Friction 3(1): 56-64 (2015)

[49] Huang G W, Yu Q L, Ma Z F, Cai M R, Zhou F, Liu W M. Oil-soluble ionic liquids as antiwear and extreme pressure additives in poly- $\alpha$-olefin for steel/steel contacts. Friction 7(1): 18-31 (2019)

[50] Stankovich S, Dikin D A, Piner R D, Kohlhaas K A, Kleinhammes A, Jia Y Y, Wu Y, Nguyen S T, Ruoff R S. Synthesis of graphene-based nanosheets via chemical reduction of exfoliated graphite oxide. Carbon 45(7): 1558-1565 (2007)

[51] Soltanahmadi S, Morina A, van Eijk M C P, Nedelcu I, Neville A. Investigation of the effect of a diamine-based 
friction modifier on micropitting and the properties of tribofilms in rolling-sliding contacts. J Phys D Appl Phys 49(50): 505302 (2016)

[52] Heuer J K, Stubbins J F. An XPS characterization of $\mathrm{FeCO}_{3}$ films from $\mathrm{CO}_{2}$ corrosion. Corr Sci 41(7): 1231-1243 (1999)

[53] Sampath S, Maydannik P, Ivanova T, Homola $T$, Sillanpää M, Nagumothu R, Alagan V. Structural and morphological characterization of $\mathrm{Al}_{2} \mathrm{O}_{3}$ coated macro-porous silicon by atomic layer deposition. Thin Solid Films 616: 628-634 (2016)

[54] Boonprakob N, Wetchakun N, Phanichphant S, Waxler D, Sherrell P, Nattestad A, Chen J, Inceesungvorn B. Enhanced visible-light photocatalytic activity of g- $\mathrm{C}_{3} \mathrm{~N}_{4} / \mathrm{TiO}_{2}$ films. J Colloid Interface Sci 417: 402-409 (2014)

[55] Erdem B, Hunsicker R A, Simmons G W, Sudol E D, Dimonie V L, El-Aasser M S. XPS and FTIR surface characterization of $\mathrm{TiO}_{2}$ particles used in polymer

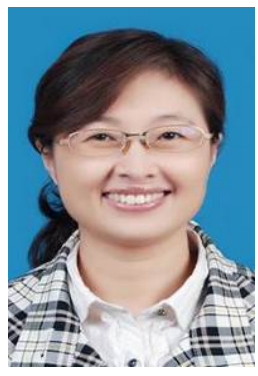

Qingjuan WANG. She received her Ph.D. degree from Xi'an Jiaotong University, China, in 2009, majoring in materials processing engineering. She has published more than 70

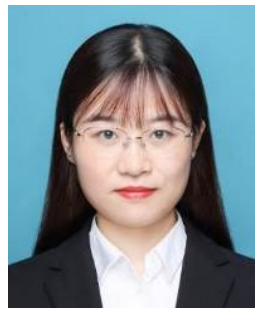

Tingli HOU. She received her bachelor degree from Xi'an University of Architecture and Technology in 2018. From 2018, she continued to earn a graduate

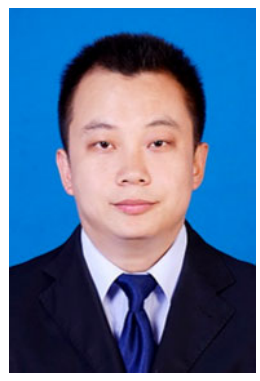

Wei WANG. He received his Ph.D. degree in materials processing engineering from Northwestern Polytechnical University, Xi'an, China, in 2015. After a two-year post-doctoral work at State Key Laboratory of Tribology of Tsinghua University, his current position is encapsulation. Langmuir 17(9): 2664-2669 (2001)

[56] Ni H, Liu X C, Cheng Q D. A new strategy for air-stable black phosphorus reinforced PVA nanocomposites. $J$ Mater Chem A 6(16): 7142-7147 (2018)

[57] Xie H M, Jiang B, He J J, Xia X S, Pan F S. Lubrication performance of $\mathrm{MoS}_{2}$ and $\mathrm{SiO}_{2}$ nanoparticles as lubricant additives in magnesium alloy-steel contacts. Tribol Int 93: 63-70 (2016)

[58] Guo P F, Qi S S, Chen L, Gou C X, Lin B, Lu Z B, Wu Z G, Zhang G A. Black phosphorus-graphene oxide hybrid nanomaterials toward advanced lubricating properties under water. Adv Mater Interfaces 6(23): 1901174 (2019)

[59] Fujita H, Spikes H A. Study of zinc dialkyldithiophosphate antiwear film formation and removal processes, Part II: Kinetic model. Tribol Trans 48(4): 567-575 (2005)

[60] Hwang Y H, Myung B S, Kim H J. Study on frictional behavior of carbon nanotube thin films with respect to surface condition. Friction 6(4): 432-442 (2018)

academic papers, including more than 40 SCI/EI indexed papers. Her major research areas include rare metal material processing and the preparation of metal ultrafine material.

degree at Xi'an University of Architecture and Technology, majoring in materials processing engineering. She published one academic paper indexed by SCI and obtained two national invention patents in 2019-2020.

an associate professor from Xi'an University of Architecture and Technology. He has published more than 30 papers indexed by SCI as the first author, worn "Tianjin Innovation Talent Promotion Program" in Tianjin in 2019, and "Outstanding Young Talents" of Shanxi Universities in 2020. His major research areas include lubrication in material processing and nanolubrication. 


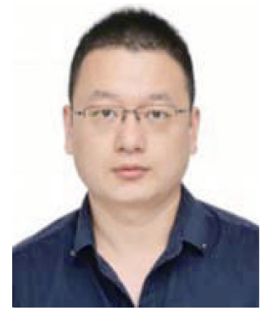

Guoliang ZHANG. He received his Ph.D. degree in chemical engineering and technology from China University of Petroleum, Beijing, China, in 2016. After a twoyear post-doctoral work at the State Key Laboratory of Tribology of Tsinghua University, he is currently an associate

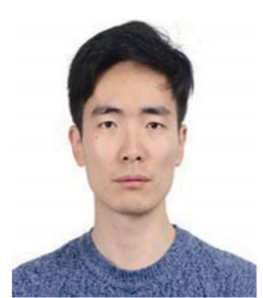

Yuan GAO. He got his bachelor and Ph.D. degrees from Tsinghua University, China, in 2011 and 2016, respectively, majoring in mechanical engineering. After

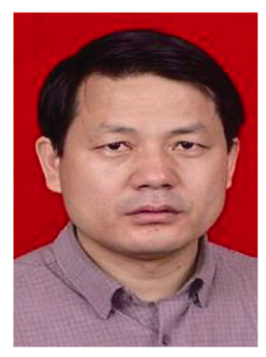

Kuaishe WANG. He received his $\mathrm{Ph} . \mathrm{D}$. degree in materials science and engineering from $\mathrm{Xi}^{\prime}$ an Jiaotong University, China, in 2009. $\mathrm{He}$ is a professor at $\mathrm{Xi}^{\prime}$ an University of Architecture and Technology. He has published 250 academic professor from Tianjin University of Technology and Education. He has published more than 10 papers indexed by SCI as the first author and worn "Youth Reserve Talent Support Plan" in Tianjin in 2019. His main research areas are intelligent lubrication systems, material design and development and control of friction, and wear performance of composite materials.

that, he has been working at Xi'an University of Architecture and Technology University as an associate professor. His main research interests include material processing tribology and selflubricating composite coating.

papers, more than 130 of which are indexed by SCI. More than 70 national invention patents have been authorized. He has edited five teaching materials and published one monograph. His major research areas include processing and theory of rare metal materials and advanced materials welding and joining technology. 